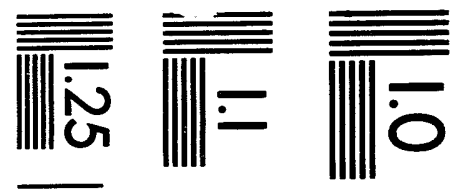

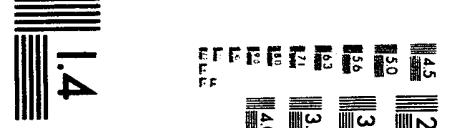

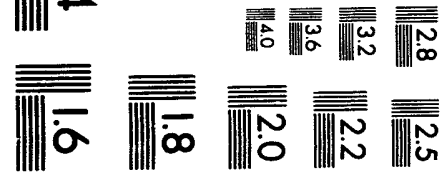



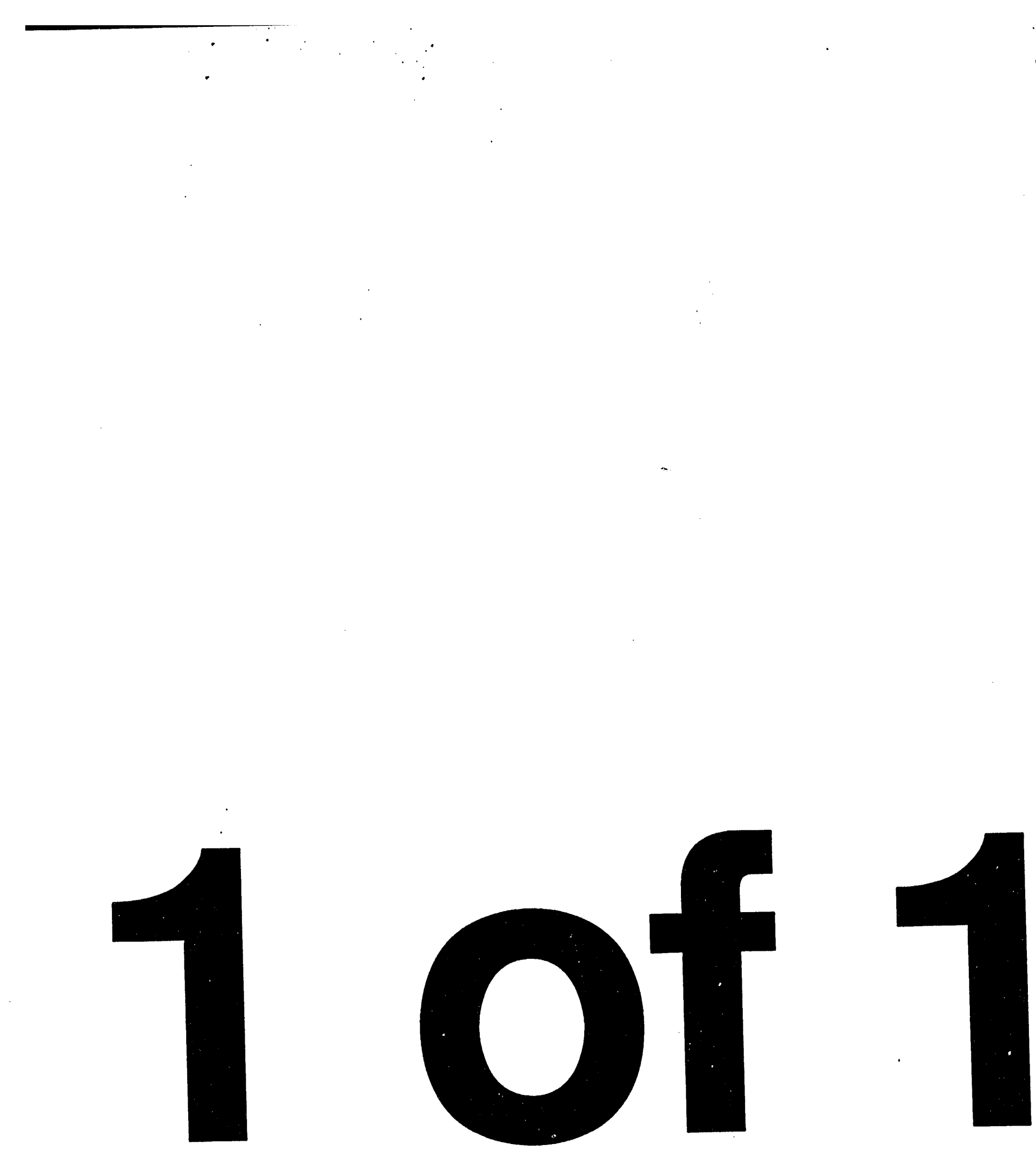
LA-UR- 93-4136

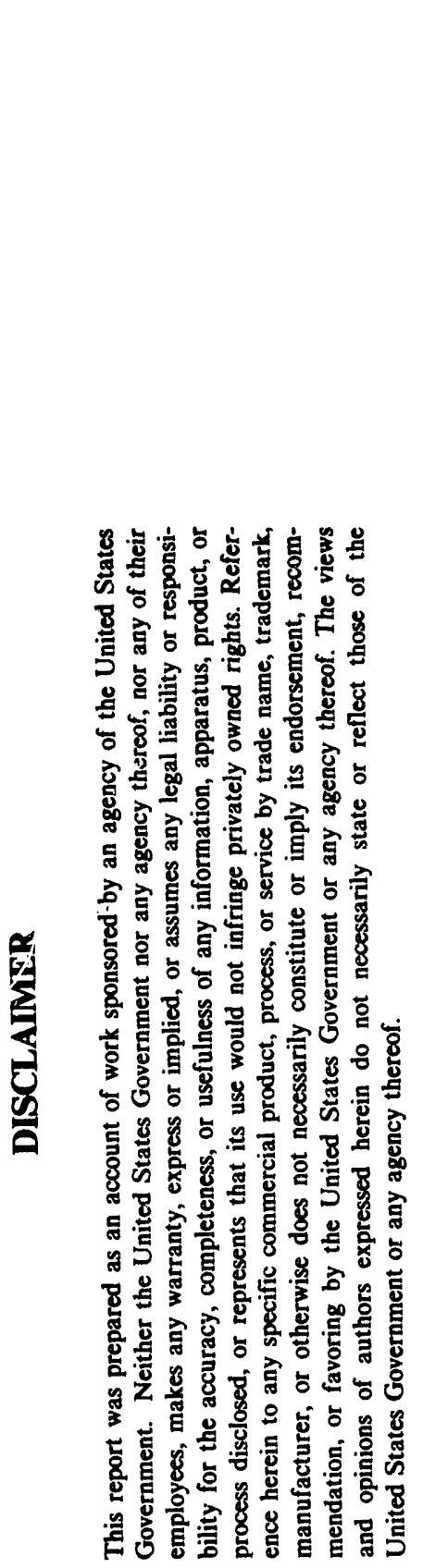

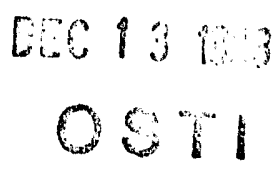

Author(s):

Submitted to:

11 th Symposium on Space Nuclear Power and Propulsion Conference

Albuquerque, New Mexico

January 9-13, 1994

Darry1 P. Butt, MTL-6

D.G. Pelaccio, UNM

Mohamed S. El-Genk, UNM

A REVIEW OF CARBIDE FUEL CORROSION FOR NUCLEAR

THERMAL PROPULSION APPLICATIONS

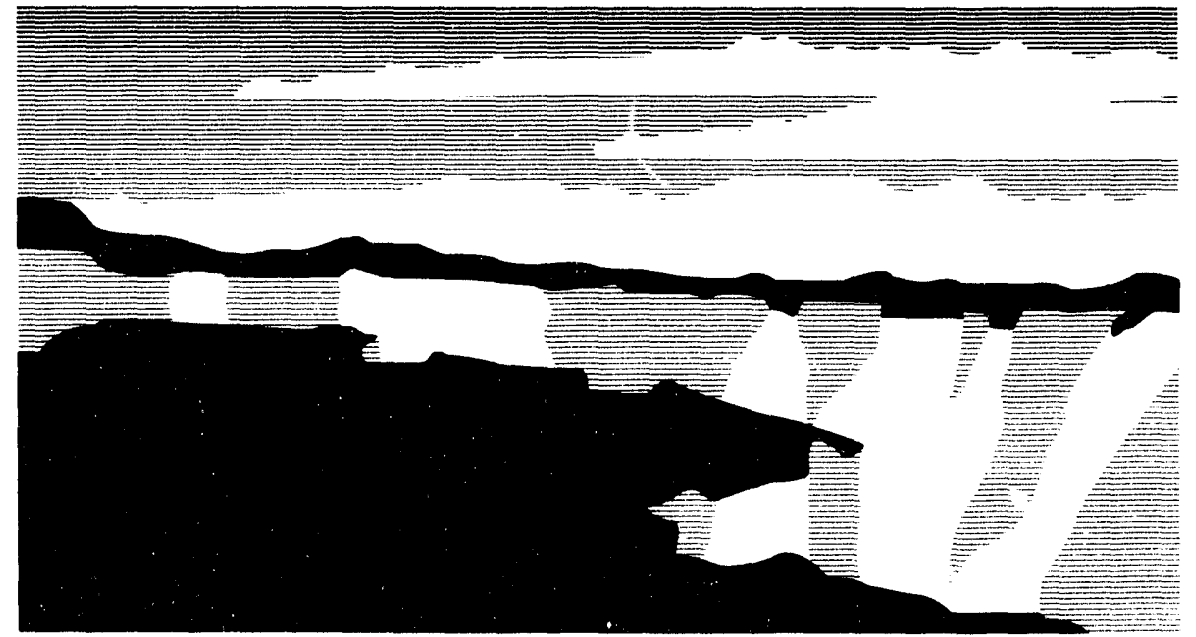

Los Alamos National Laboratory, an affirmative action/equal opportunity employer, is operated by the University of California for the U.S. Department of Energy under contract W-7405-ENG-36. By acceptance of this articie, the publishor recognizes that the U.S. Government retains a nonexclusive, royalty-free license to publish or reproduce the published form of this contribution, or to allow others to do so, for U.S. Government purposes. The Los Alamos National Laboratory requests that the publisher identify this article as work performed under the auspices of the U.S. Department of Energy. 


\title{
A REVIEW OF CARBIDE FUEL CORROSION FOR NUCLEAR THERMAL PROPULSION APPLICATIONS
}

\author{
Dennis G. Pelaccio and Mohamed S. El-Genk \\ Institute for Space Nuclear Power Studies \\ The University of New Mexico \\ Albuquerque, NM 87131-1341 \\ (505) $277-5635 / 5442$
}

\author{
Darryl P. Butt \\ Material Science Technology Division \\ Los Alamos National Laboratory \\ Los Alamos, NM 87544 \\ (505) 667.9307
}

\begin{abstract}
At the operation conditions of interest in nuclear thermal propulsion reactors, carbide materials have been known to exhibit a number of life limiting phenomena. These include the formation of liquid, loss by vaporization, creep and corresponding gas flow restrictions, and local corrosion and fuel structure degradation due to excessive mechanical and/or thermal loading. In addition, the radiation environment in the reactor core can produce a substantial change in its local physical properties, which can produce high thermal stresses and corresponding stress fractures (cracking). Time-temperature history and cyclic operation of the nuclear reactor can also accelerate some of these processes. The University of New Mexico's Institute for Space Nuclear Power Studies, under NASA sponsorship bas recently initiated a study to model the complicated hydrogen corrosion process. In support of this effor, an extensive review of the open literature was performed, and a technical exper workshop was conducted. This paper summarizes the results of this review.
\end{abstract}

\section{INTRODUCTION}

Nuclear Thermal Propulsion (NTP) engine systems are attractive options for orbit transfer and planetary exploration applications because of their high performance (Bussard and DeLauer 1965, Borowski et al. 199.2, and Stafford et al. 1991). To achieve such performance, which is typically over twice that associated witbin chemical propulsion systems, hydrogen is used as the NTP engine system working fluid because of its low molecular weight. In the operation of such systems, NTP reactor chamber temperatures and pressures are typically greater than $2500 \mathrm{~K}$ and $3 \mathrm{MPa}$, respectively. Additionally, to minimize the weighth NTP reactors operace at bigh power densities. Power densities of up to $2.7 \mathrm{MW}$ /iter have been demonstrated, while future generation solid-core reactor concepts could conceivability operat: at power densities as high as $10 \mathrm{MW}$ /iter or greater for single ourth, short operation time applications (Koenig 1986 and Clark et al. 1993). Operating at these bigh power densities produces a high radiation flux environment in the reactor core. These characteristics provide a tustile envifonment for NTP reactor core materials in which to survive. To meet this engineering challenge, Uranium-Z irconjivis-Carbon ( $)-Z \mathrm{r}-\mathrm{C}$ ) and Uranium-Niobium-Carbon (U-Nb-C) material systems have been considered for ucb slications (Knenxg 1986, Finseth 1991, Taub 1975, Lyon 1973, Matthews et al. 1991. Carmack et al. 199\%, How an et 2l. 1991 and Storms et al. 1991). Carbide material systems are attractive due to their favorable nucle is gr opertias, bi : thelting point, thermal stability, low volatibility, high moderation properties, and low density.

At the operation conditions of interest in NTP reactors, carbide materials bave fyen IT Gwn wo exhibit a number of life limiting phenomena (Storms et al. 1991). These include the formation of beuid ' $195, k$ vaporization, creep and corresponding gas flow restrictions, and local corrosion and fuel structure dit, iadstjitit due to escessive mechanical and/or thermal loading. In addition, the radiation in the reactor core environment en sinduce 6 substantial change in its local physical properties, producing high thermal stresses and corresponding stro fractsys (cracking). Timetemperature history and cyclic operation of the nuclear reactor can also accelerate $20 \mathrm{k}: \mathrm{se}$ yrocesses.

Degradation of NTP reactor fuel integrity by the physical processes just mentiored, has been the subject of research and development during reactor testing associated with the Rover and NERVA programs (Koenig 1986. Finseth 1991, Taub 1975, Lyon 1973, and Homan et al. 199i). Of most concern was the core material mass loss associated with localized corrosion of the prismatic design fuel elements used in these programs. Material mass loss occurred at temperatures substantially lower than the fuel material melting temperature $(2500 \mathrm{~K}$ vs. $3200 \mathrm{~K})$ and accounted for a large percentage of the core material loss during operction. This highly complex phenomena encompassed many of the life-limiting processes previously discussed, and made engineering solutions to correct this

Presented at the 11th Symposium on Space Nuclear Power and Propulsion Conference, held 9-13 January 1994, Albuquerque, NM 
problem difficult to identify and implement. The bydrogen corrosion process substantially reduces NTP engine system performance and life, which directly influences overall mission safety, reliability, and cost.

\section{OBJECIIVE}

The University of New Mexico's (UNM) Institute for Space Nuclear Power Studies (ISNPS), under NASA sponsorship has recently initiated a study to model the complicated bydrogen corrosion process. In support of this effort, an extensive review of the open literature was performed and a technical expert workshop was conducted. These study activities helped to provide the foundation to establish the state-of-the-art understanding of the physical processes and modeling of corrosion of carbide material systems when exposed to hot hydrogen at conditions typical of NTP reactors. Additionally, the review assessed the applicability of available experimental data to benchmark (verify) future corrosion models. This paper summarizes the results of the review.

An extensive open literature review was performed during this initial study. In this effort, literature was gathered and reviewed principally in the areas of carbide thermochemistry and in related research and development work associated with the NERVA and Rover programs. In addition, extensive discussions were held with many technical experts in this field. Based on this data gathering activity, assessment was made on of the technical community's past experience, fundamental understanding of the complex corrosion process, and the adequacy of available experimental data to properly benchmark the next generation of corrosion model(s). The following section summarizes the results of this review.

\section{RESUITS}

Corrosion of carbide fuel materials, due to their exposure to hot hydrogen in NTP systems greatly impacts the engine performance, thrust-to-weight, and operation life and is considered by many to be a critical development issue. Experience from the Rover and NERVA programs have shown the effects of corrosion to be substantial and to be highly complex. Hydrogen corrosion phenomena of carbon-based structual materials and carbide fuels are driven by many highly coupled and interrelated physical processes. These processes include: (1) exposure to hot bydrogen gas which produces thermo-chemical reactions of various types, (2) preload and non-uniform heating and mechanical loading. (3) exposure to nuclear radiation, and (4) high temperature effects such as creep. Coatings have been used in the past to combat corrosion, but with only moderate success.

As shown in Figure 1, corrosion has a major impact on NTP engine system design, development, and operation, including: (1) specific impulse, (2) engine system thrust-to-weight ratio, (3) reactor control, (4) operational life, and/or duty cycle, and (5) ground testing complexity and cost.

For solid-core reactor engine systems, bydrogen corrosion limits the reactor exit gas temperature for a given operational lifetime and duty cycle. Corrosion of high-temperature carbide solid-solution systems have been found to exist at temperatures $(<2400 \mathrm{~K}$ ) substantially less then their melting points $(>3200 \mathrm{~K}$ ). The reactor exit (chamber) temperature substantially impacts engine system performance, and specific impulse (Bussard and DeLauer 1965). Thus, as the propellant exit temperature increases, mission propellant mass and support (launch system) infrastructure requirements decrease, reducing the overall mission life cycle cost. Additionally, the occurrence of corrosion during operation can slighty reduce the engine system performance by increasing the molecular weight of the propellant gas working fluid by entrainment of the beavier reactor fuel and structual material and its reaction byproducts (Bussard and DeLaver 1965).

Hydrogen corrosion affects the thrust-to-weight ratio of the engine system in two ways: (a) it increases the initial reactor core mass to compensate for mass loss during its operation lifetime, and (b) it lowers the reactor power density, resulting in a lower engine system thrust-to-weight ratio and/or limits on given system operational lifetime and duty cycle. The relationship between power density and critical size of the core greatly influences engine system life for a given fuel design.

Mass loss of the reactor core fuel by corrosion also increases the demand (adaptative response) of the reactor control system which can reduce the reliability and safety of the NTP engine system (Koenig 1986 and Taub 1975). The reactor core neutronics will vary as a function of operating time (parasitic absorption and scatuering will change) within the core as the moderator and/or fuel material is removed by corrosion. These factors, which change the reactivity feedback characteristics and reactor period, will likely challenge its control system. 


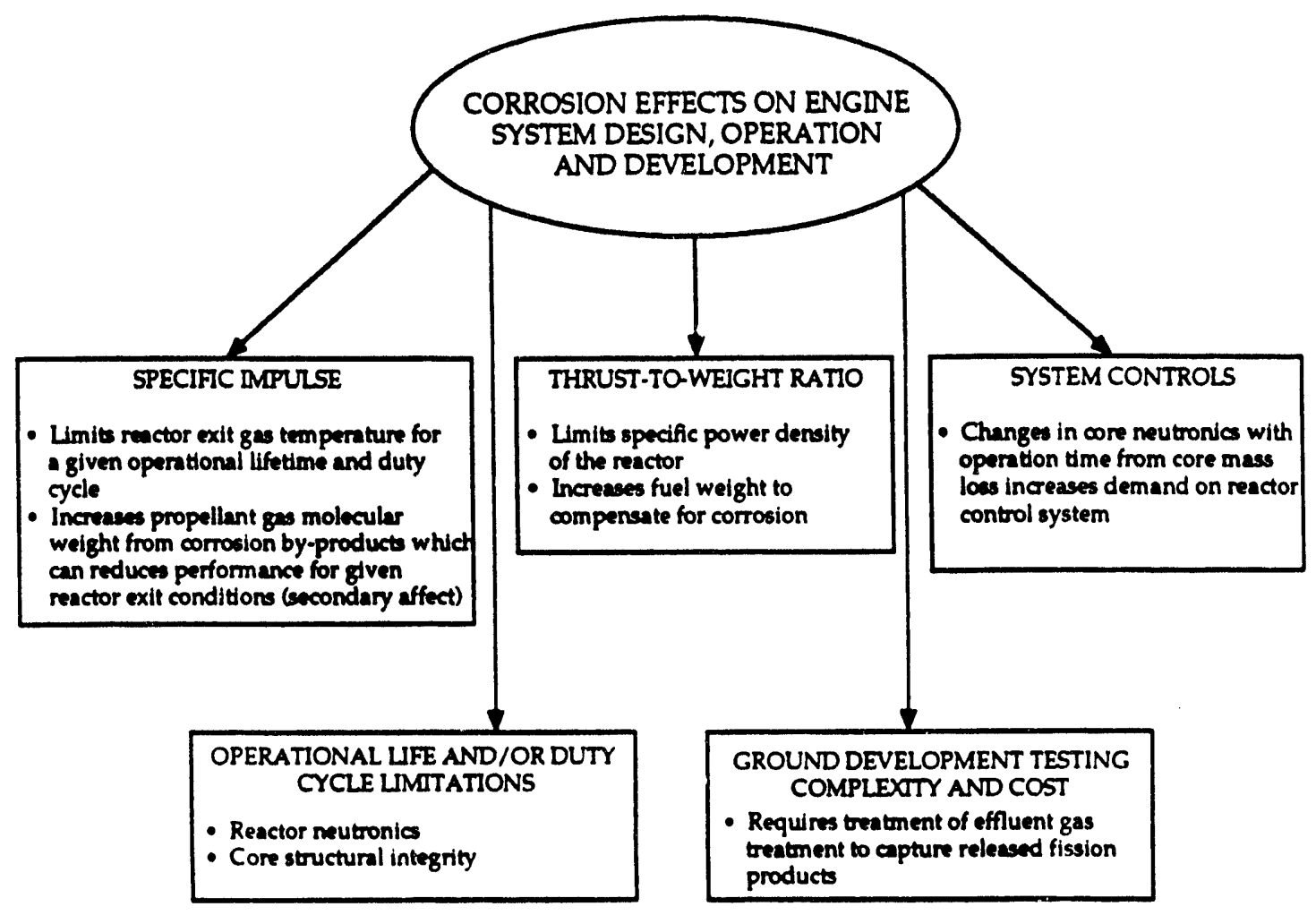

FIGURE 1. Effects of Hydrogen Corrosion on a Nuclear Thermal Propulsion Engine System.

For a given NTP reactor design with a particular set of operating conditions, duty cycle life-limiting effects such as residual stress buildup and/or low temperature bydriding of the carbide fuel, coupled with corrosion, can reduce the operational life of the system. (Koenig 1986, Finsetb 1991, Taub 1975 and Lyon 1973). The release of NTP reactor fuel (fission products) into the atmosphere and surrounding ground test area is unacceptable from an environmental viewpoint. Thus, containment and collection of NTP system fission byproducts effluent requires that an effluent exhaust gas treatment system be used, increasing the complexity and cost of the test system.

U-Zr-C fuel material has been used in a number of fuel element designs for NTP reactor systems which are summarized in Table 1. A particular core fuel design can affect the local propellant (hydrogen) flow, material temperature, radiation flux, surface area-to-volume characteristics, size and mass of the reactor, and internal stress considerations. These inherit design traits interact in a high!'y-coupled, integrated manner with the many competing corrosion processes, on both \& local (micro) and global (macro) scale.

The first fuel element design shown in Table 1 were developed and studied extensively during the Rover and NERVA programs (Clark et al. 1993, Finseth 1991, Taub 1975, and Lyon 1973). Typically, each fuel element contains 19 small, axial circular coolant channels. Fuel elements of this type were fabricated and tested with different U-Zr-C fuel designs and compositions. Figure 2 displays the principle fuel design examined in the Rover and NERVA programs. Uranium fuels in the past were embedded in: a graphite matrix in the form of $\mathrm{UO}_{2}$ (not shown) or UC 2 particles as a continuous UC webbed dispersion, and as a U-Zr-C solid-solution. Development test reactor experience showed these types of fuel designs to be susceptible to bydrogen corrosion. Hydrogen corrosion was found to occur primarily in the small coolant channels, about the outer periphery of the fuel element, where bydrogen gas leakage was observed, and at the fuel element support cup region, (see Figure 2) (Koenig 1986, Finseth 1991, and Taub 1975). The graphite fuel elements associated with NRX-A6 reactor test of the NERVA program, were considered the most successful (Koenig 1986, Finseth 1991 and Taub 1975). The Nuclear Furnace-1 (NF-1) demonstrated better bot end corrosion than the graphite fuel elements previously tested in the Rover and NERVA program, but still exhibited a significant degree of mid-band (relatively low temperature) corrosion (Koenig 1986. Taub 1975 and Lyon 1973). 
Because of the higb chemical reactivity of carbon with bot hydiogen, numerous surface coating strategies were investigated. Much of the past Rover and NERVA program efforts in this area focused on the development of effective surface over coatings, to reduce the corrosion and corresponding degradation in structural integrity of the fuel elements and non nuclear reactor core components (Koenig 1986, Finseth 1991, Taub 1975, Lyon 1973, Homan et al. 1991. Wagner 1992, and Wallace 1991). Monocarbides such as NbC and ZrC, as well as others, were considered as protective coating material candidates because of their stable interface (contact) adherence with graphite at bigh temperature, bigh eutectic temperature, relative resistance to attack by bydrogen at NTP reactor operation conditions, and low neutron cross-section (Koenig 1986, Finseth 1991, Taub 1975, Lyon 1973, Homan et al. 1991, and Wallace 1991). Fabrication processing and quality control, thermal expansion compliance between the surface coating and the fuel form substrate, and the presence of initial surface micro-cracks were found to be the key factors which influenced the effectiveness of a coating to combat corrosion (Koenig 1986, Finseth 1991, Taub 1975, Lyon 1973, Homan et al. 1991, Wallace 1991, and Kochka 1969).

TABLE 1. Typical US Nuclear Thermal Propulsion Reactor Carbide Fuel Form Designs Considered in the Past.

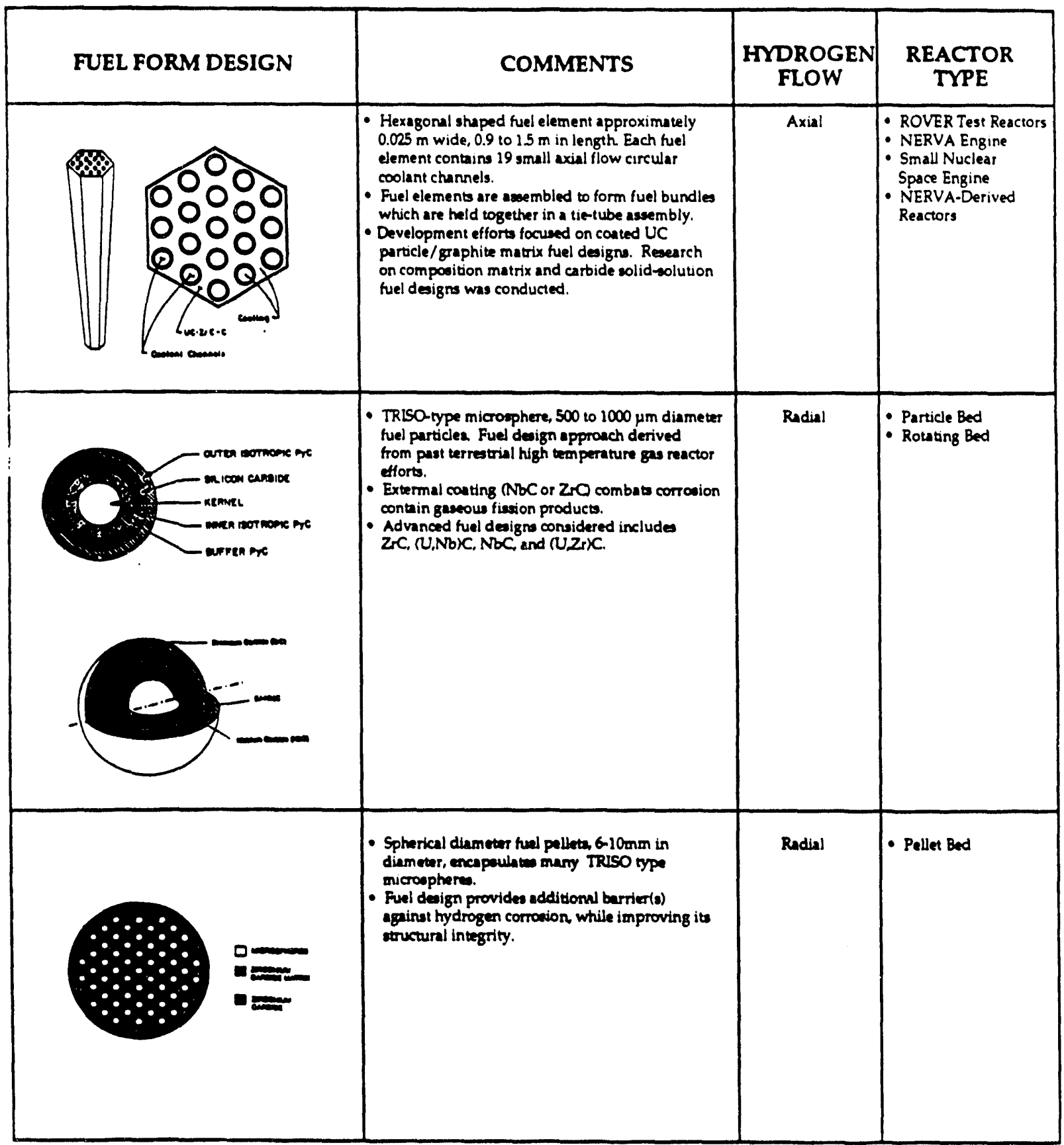



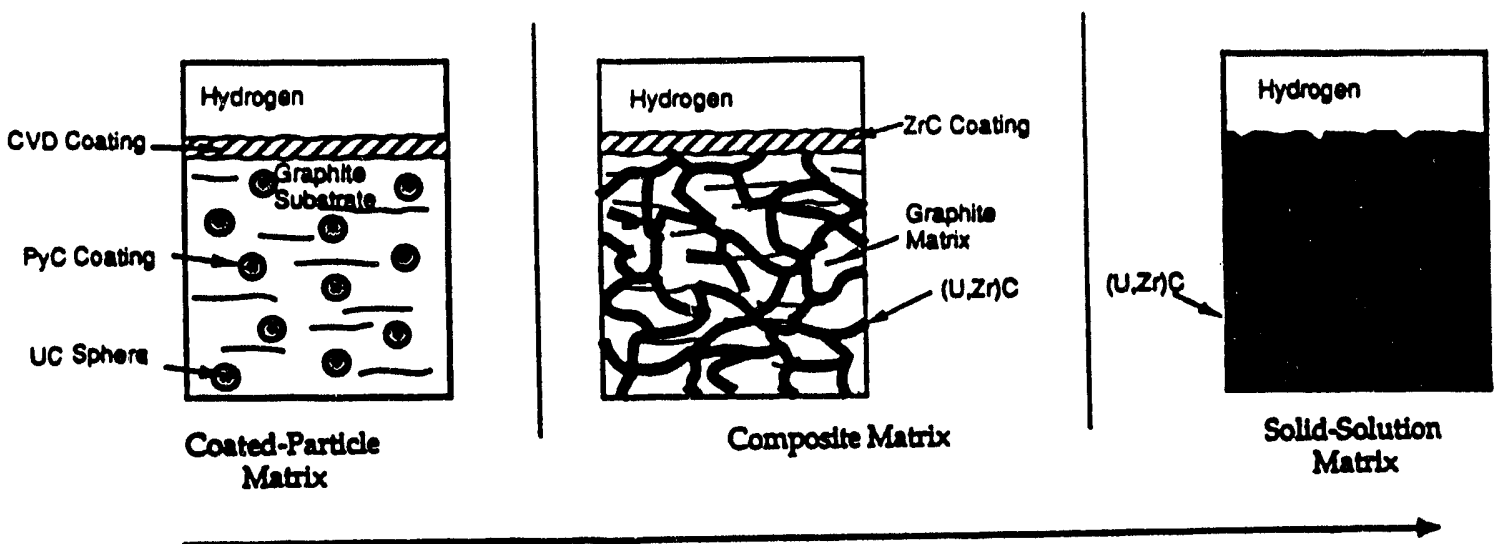

EVOUUTIONARY DEVLEOPMENT (INCRRASED TEMPBRATURB AND/OR LWFB)

FIGURE 2. Types of Carbide Based Fuel Matrix Designs Previously Considered.

The NbC surface coating was first investigated in the Rover program because of their high eutectic temperature $(-3575 \mathrm{~K})$, which is approximatly $450 \mathrm{~K}$ higher than that of $\mathrm{ZrC}(-3123 \mathrm{~K})$ (Taub 1975, Homan et al. 1991, and Wallace 1991). Early tests showed NbC coatings to have some problems associated with surface cracking and adherence with the graphite matrix fuel substrate (Koenig 1986, Finseth 1991, Taub 1975, Lyon 1973, Homan et al. 1991, Wallace 1991, and Kochka 1969). Initial research on ZrC coatings were found to adhere better to the fuel substrate than $\mathrm{NbC}$ coating. Based on this experience $\mathrm{ZCC}$ coatings were incoporated in many fuel element designs in later Rover and NERVA test reactors and engine designs. Composite fuel elements for the NF-1 tests also employed ZrC surface coatings (Taub 1975, Lyon 1973). Even with the lower eutectic temperature associated with ZrC. these coatings were found to have good resistance to carbon diffusion at high temperatures (Koenig 1986, Finseth 1991, Taub 1975, Lyon 1973, Homan et al. 1991, and Wallace 1991). Though fuel mass loss was shown to be reduced by using ZrC coatings, significant coatings surface cracking was still observed (Koenig 1986, Finseth 1991, Taub 1975, Lyon 1973, Homan et al. 1991, and Wallace 1991). The presence of these surface cracks in the coatings of fuel elements was primarily attributed to differences in the coefficients of thermal expansion (CTE) of the coating and fuel substrate materials. The CTE characteristics of some candidate fuel compositions and surface coatings considered in the Rover and NERVA programs are summarized in Table 2 . Additionally, factors such as the operational environment and duty cycle that a reactor core experiences, can also contribute to surface coating cracking.

TABLE 2. Typical Coefficient of Thermal Expansion (CTE) Values of Candidate Nuclear Thermal Propulsion Fuel Materials (Taub 1975).

\begin{tabular}{|c|c|c|}
\hline MATERIAL & APPLICATION & $\begin{array}{c}\text { CTE }(\mu \mathrm{m} / \mathrm{m} \text { K) } / \\
\text { TEMPERATURE (K) }\end{array}$ \\
\hline $\begin{array}{c}\text { Flour-Type Graphites } \\
\text { Unfueled Graphite } \\
\text { Extusions }\end{array}$ & F & $5.3-6.5 / 298-2273$ \\
\hline NbC & F & $2-4 / 293-2273$ \\
\hline ZC & C & $6.6 / \ldots .$. \\
\hline $\begin{array}{c}\text { (U, Zr)C Composite } \\
\text { Fuel Elements }\end{array}$ & C & $7.7 / \ldots$ \\
\hline $\begin{array}{c}\text { (U, Zr)C Carbide } \\
\text { Fuel Elements }\end{array}$ & F & $6-7 / 293-2300$ \\
\hline
\end{tabular}

- $C=$ Coating, F = Fuel Substrate 
The other coating strategy investigated focused on developing a fuel element which minimized and/or eliminated iIII difference in the CTE between the substrate and the coating (Koenig 1986 and Taub 1975). Near the end of the Rover program, fuel elements which exhibited such physical characteristics were fabricated, but were never tested in a reactor due to the termination of the program.

Flow instabilities, as well as substantial levels of nonuniform mechanical and thermal loading were also observed to be present in Rover type fuel designs (Koenig 1986 and Finseth 1991). On the positive side, this type of fuel design exhibited a rather low surface area-to-volume ratio which tends to reduce the overall effect of corrosion on the operation of the NTP engine system. Much of the fuel technology and experience base gained from the Rover and NERVA programs has applicability to the fundamental understanding and development of other emerging NTP reactor concepts.

The use of small microsphere fuel particles has also been considered for a number of packed bed NTP reactor concepts (Clark et al. 1993, Bous et al. 1983, and El-Genk et al. 1993). Typically these particles, shown in Table 1 , are approximately 500 to $1000 \mu \mathrm{m}$ in diameter and are composed of an inner fuel kernel made up of UC $\mathrm{X} / \mathrm{ZC}$ or $\mathrm{UC}_{\mathrm{X}} / \mathrm{NbC}$ bydrogen corrosion resistant materials which are multicoated with high strength, high temperature over coatings such as porous carbon, pyrolytic carbon, and ZrC. These particles are designed to withstand the internal pressure buildup due to fission gas (mostly $\mathrm{Xe}$ and $\mathrm{Kr}$ ) production, as well as to withstand the reactor core environment. Such small paricles possess a high surface area-to-volume ratio, which can enable operation at high power densities, but at the expense of rapid mass loss by hydrogen corrosion (Storms 1991 and Clark et al. 1993).

Anowher carbide fuel form design that bas been examined in the past is the fuel pellet (Clark et al. 1993 and El(ienk $\mathrm{cl}$ al. 1993). The fuel pellec shown in Table 1 , is typically 5 to $10 \mathrm{~mm}$ in diameter, which is made up of many UC.ZrC or UC-NbC fuel, TRISO-type, mictospheres, and has an over coat of ZrC or NbC, respectively. This fuel parucles are then encapsulated in a $\mathrm{Z} \times \mathrm{C}$ matrix which is also coated with an additional layer of $\mathrm{ZrC}$ to provide additional protection against bydrogen corrosion. The fuel pellet design provides a more uniform temperature distribution, avoids high contact point stresses between microspheres, offers multiple structural barriers to ensure full tission product retention, and provides high resistance to corrosion by bydrogen. Packed bed reactor concepts Uhat use this tuel form typically exthibit a medium tuel surface area-to-volume ratio, and produce reactor power densities (2-4 MW/iter) that are greater than those demonstrated in the Rover and NERVA programs. Because of the substantially lower surface-to-volume ratio of these pellets, they would exhibit substantially less fuel mass loss by corrosion than in a particle bed reactor.

The development test reactors, the NERVA, and Small Nuclear Space Engine flight designs, all used fuel elements that were based on the coated-particle matrix design (Figure 2) (Koenig 1986). Tests results showed that fuel mass loss and mechanical degradation were major development issues and the potential of increasing the reactor operating temperature was marginal. Hence. The composite matrix and solid-solution fuel designs were pursued (Figure 2) during the later portion of the Rover program. These fuel designs bave the potential to operate at bigher temperatures, as well as being more resistant to bydrogen corrosion than coated-particle designs. The bigh temperature potential of a solid-solution fuel composition can be understood by examining a pseudo-binary phase diagram of such a carbide material, $\left(\mathrm{U}_{0.1}, \mathrm{Z}_{0.9}\right) \mathrm{C}_{\mathrm{x}}$, which is displayed in Figure 3 (Lyon 1973). With in a small carbon atom ratio range ( 0.92 to 0.96$)$, material temperatures greater than $3100 \mathrm{~K}$ are possible. Conversely, Figure 3 shows that the melting point of $\left(\mathrm{U}_{0.1}, \mathrm{Zr}_{0.9}\right) \mathrm{C}_{\mathrm{X}}$ is sensitive to a change in carbon content, which could vary dunng operation if bydrogen corrosion takes place. By increasing interspersion of the fuel into the graphite matrix a closely packed webbed type structure is produced (Figure 2), the propagation of cracks can be limited. Limited development testing of these altemative fuel designs were performed in the Nuclear Furnace research reactor. Based on these limited results for modest NTP operation life, these alternative fuel compositions could likely operate at reactor gas temperatures $\geq 2700 \mathrm{~K}$ for the composite design and $\geq 2900 \mathrm{~K}$ for the solid-solution design (Taub 1975). Operating temperatures for these advanced fuel designs can be compared to the coated-paricle matrix fuel which operate up to a maximum gas temperature of $2500 \mathrm{~K}$. These temperatures are also a few hundred degrees higher than that associated with coated fuel microspheres. The increased operating temperature capability of these advanced fuel designs can translate into increased NIP engine system performance, design margin (reliability and safety) and/or life.

A comparison of the mass loss rate, as a function of fuel element axial position, for Pewce-1 graphite and NF-1 composite test reactor elements are displayed in Figure 4 (Lyon 1973). Figure 4 shows the average mass loss rate as a function of coolant channel position for (A) 102 Pewee-1 graphite fuel elements coated with NbC, (B) 12 Pewee-1 graphite fuel elements coated with $\mathrm{ZrC}$, and (C) $23 \mathrm{NF} \cdot 1$ composite fuel elements coated with $\mathrm{Z} \mathrm{C}$. The data bas 
he'll adjusted in lake into account the differences in operating temperatures between the 2 reactors. The Pewee- 1 fuel elements had coolant channel surfaces which were coated with either NbC or ZrC, while the NF-1 test composite luel was coated with $\mathrm{ZrC}$. Peak mass loss rates in the mid-band corrosion region, (at low temperature) for the compusite fuel element were 13 to 17 percent lower, depending on the Pewee- 1 fuel element design considered. The high mass loss rates observed in the low temperature region have been atuributed to the presence of initial surface coaung cracks and the difference in CTE's of the coating and the fuel substrate materials. The reduction in observed mass loss rate downstream of the peak rate region (at higher fuel temperature) indicates that the differential in the CTE of the coating and the fuel substrate materials are such that the surface coating is in compression relative to the fuel substrate. This condition tends to close surface cracks which are pocential corrosion sites. Likewise, the corrosion byproducts, sucb as $\mathrm{CH}_{4}$ and $\mathrm{C}_{2} \mathrm{H}_{2}$, in the hydrogen coolant gas stream, the deposite of these byproducts on the coolant channel surface, as well as the shifting surface composition, an reduce the chemical driving potential for corrosion (Koenig 1986, Taub 1975, Wallace 1991, MacMillan 1991, Sworms 1992 and Butt 1992).

Composite fuel element mass loss rates at the hotter, downstream axial element positions are also substantially lower than those typical for the Pewee-1 elements (Figure 4). Mass loss observed in the higb temperature regions is dominated by the vaporization of it's elemental material constitutes (Koenig 1986, Taub 1975, Wallace 1991, MacMillan 1991, Storms 1992 and Butt 1992). Like the mid-band corrosion region, surface coating integrity, and the chemical composition of the coolant gas and the fuel surface, are major factors which influence the corrosion process in this region

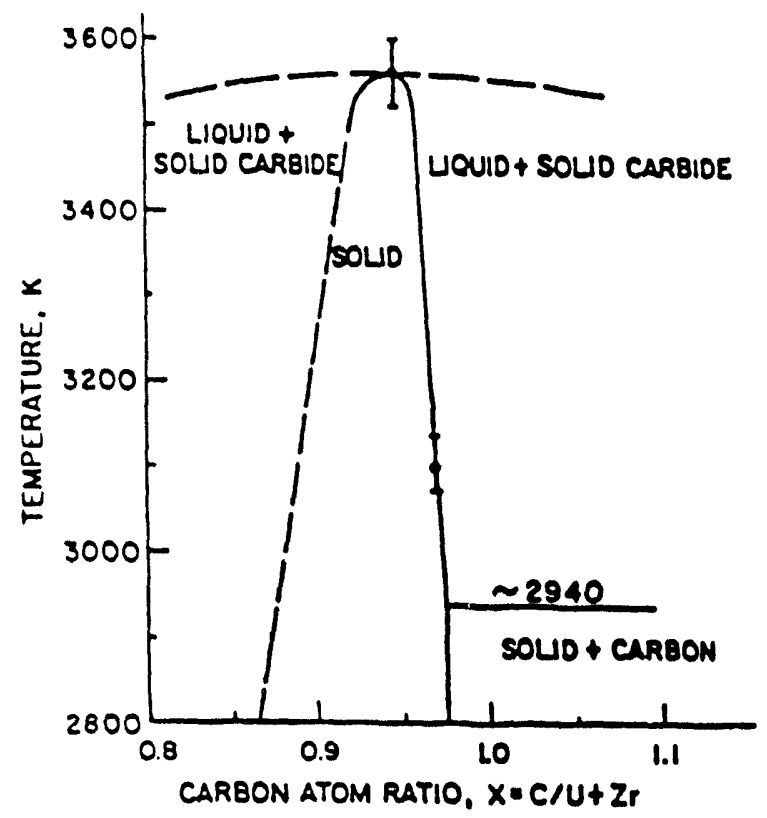

FIGURE 3. Pseudo-binary Phase Diagram of $\left(\mathrm{U}_{0.1}, \mathrm{Zr}_{0.9}\right) \mathrm{C}_{\mathrm{x}}$ (Lyon 1973).

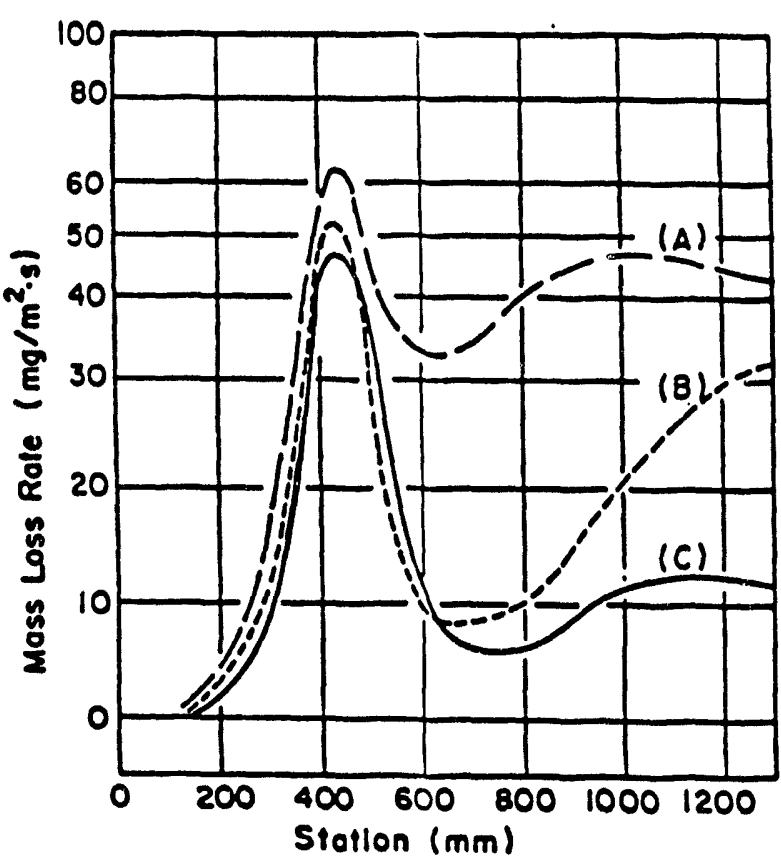

FIGURE 4. Mass Loss Rate for Graphite and Composite Fuel Elements (Lyon 1973 and Taub 1975).

It was fuel mass loss observations like those just discussed, througbout the Rover and NERVA programs, which indicated to the scientist and engineers at the time that the bydrogen corrosion process associated with NTP reactor fuels is highly complex and is difficult to quantify fully from a fundamental viewpoint. In addition to the complex chemical corrosion processes inherent with a carbide/hot bydrogen gas system, other physicalmechanical processes such as fuel/material design and fabrication, nuclear radiation exposure, and local coolant flow conditions, can greatly influence the corrosion process (and corresponding fuel mass loss). Because of the many highly interrelated, complex physical processes and mechanical design features which influence the corrosion of NTP carbide systems, accurate fundamental modeling of the overall process is a major challenge, especially for coated fuel designs. 
The avaulability of relevant experimental data to benchmark corrosion model(s) is limited (Table 4). It should be noted that this data base summarized in Table 4, is based principally on open literature on the United State's (US) past experience. The University of New Mexico plans on continuing this effort by augmenting this data base with the Russian experience. A joint research and development effort between UNM-ISNPS and the Russian Research and Development Institute of Power Engineering (RDIPE) was initiated in the Fall of 1993 . Results from this joint effor will be reported at a later date.

Subscale thermochemical, arcjet, and heated tube, single-effects experiments (Table 4) provide data on one or more fundamental aspects of the hydrogen corrosion process with carbide materials. Many of these experimeats were conducted at test (exposure) conditions less demanding than those typically encountered in an operational NTP reactor, but were well controlled. This data is valuable, but lacks quantitative insight into some of the fundamental competing (highly coupled) processes associated with hydrogen corrosion. Also, scaling laws for applying these tests results to operational NTP reactor conditions have not been developed. This would be a difficult task because of the complexity (and coupling) of the many corrosion processes at work. Thus, the usefullness of this data to benchmark corrosion models is bighly uncertain, but would likely be used as a starting point for future modeling efforts.

The data base associated with past research and engine reactor tests contains a wealth of information, but is of a qualitative nature (Koenig 1986, Finseth 1991 and Taub 1975). Many of the qualitative observations pertaining to fuel corrosion and integrity from the prototype engine reactor tesis are summarized in Table 5 . Because these tests were performed with NTP reactors, at true operational conditions, instrumentation measurements, and independent control of reactor parameters were limited. Much of this experimental data base is of litule use for initial corrosion model verification, because single cause and effects corresponding to a paricular corrosion process is difficult to deduce. The data associated with the NF-1 test is believed to be the best quantitative data available on bydrogen corrosion and structural performance of NTP fuels at true operational conditions (Taub 1975 and Lyon 1973). Unfortunately this data base is limited in terms of quantity.

TABLE 4. Sources of Supporting Data and Literature Related to Hydrogen Corrosion of Carbides.

\begin{tabular}{|c|c|}
\hline CATEGORY & REFERENCES \\
\hline $\begin{array}{l}\text { Research Reactor/Prototype } \\
\text { Engine Reactor Tests } \\
\text { - Rover and NERVA Programs }\end{array}$ & $\begin{array}{l}\text { Finseth }(1991)^{*}, \text { Koenig }(1986)^{*}, \text { Lyon }(1973)^{*}, \text { Taub } \\
(1975)^{*}, \text { Wagner }(1992)^{*} \text {. }\end{array}$ \\
\hline $\begin{array}{l}\text { Subscale Hydrogen/Carbide Material } \\
\text { Experiments } \\
\text { Primarily Based on Arcjet and Heated } \\
\text { Tube Experiments (Part of the Rover } \\
\text { Program) }\end{array}$ & $\begin{array}{l}\text { Burghardt }(1965)^{*} \text {, Chi (1965)*, Juveland et al. (1963), } \\
\text { MacMillan (1991) }{ }^{*} \text {, Taub (1975) }{ }^{*} \text {, Wagner (1992)*. }\end{array}$ \\
\hline $\begin{array}{l}\text { Supporting Physical Fundamental } \\
\text { Properties of Carbide and Related Materials } \\
\text { - Phase States } \\
\text { - Vaporization } \\
\text { - Diffusion } \\
\text { - Thermal Conductivity } \\
\text { - Coefficient of Thermal Expansion } \\
\text { - Creep }\end{array}$ & $\begin{array}{l}\text { Andrievski et al.969), Butu (1992), Butt et al. (1993), } \\
\text { Fedrov etal. (1972), Fries (1962), Green (1959), } \\
\text { Kempter et al. (1960), Lyon (1973)*, Nikol'skaya et al. } \\
\text { (1968), Samsonov (1974), Santandrea (1993), Storms } \\
\text { (1967, 1992), Storms et al. (1969, 1973a, 1973b, } \\
\text { 1973c), Tobin et al. (1965), Wallace (1991), Wallace et } \\
\text { al. (1993). }\end{array}$ \\
\hline $\begin{array}{l}\text { Effects of Radiation of Carbide and } \\
\text { Related Materials } \\
\text { - Primarily Based on the Radiation } \\
\text { Effects of Graphite Material } \\
\text { Propery } \\
\text { - Behavior of Fission Products Included }\end{array}$ & $\begin{array}{l}\text { Bokor et al. (1991), Childs et al. (1963a, 1963b), Dahl } \\
\text { et al. (1965), Dabl (1966), Davidson et al. (1965, } \\
\text { 1966), Degal'tsev et al. (1987), Freas et al. (1961), } \\
\text { Hunter (1959), Lyon (1973), Nightingale (1962, 1964), } \\
\text { Roberston (1969), Roesmer et al. (1967)*, Sayers et al. } \\
\text { (1963), Simmons et al. (1965), Taylor et al. (1969), } \\
\text { Taub (1975)*. }\end{array}$ \\
\hline $\begin{array}{l}\text { Hydrogen Reaction Kinetics } \\
\text { - Almost All Work Has Focus on the } \\
\text { Hydrogen-Caron Chemical Reaction } \\
\text { System }\end{array}$ & $\begin{array}{l}\text { Burghardt }(1965)^{*} \text {, Chi }(1965)^{*} \text {, Chi et al. (1968)*, } \\
\text { Clarke et al. (1967), Krakowski et al. (1968), Rodgers } \\
\text { et al. (1986)*, Sanders (1965). }\end{array}$ \\
\hline
\end{tabular}

* Highly Applicable wo Hydrogen Corrosion of Carbides for Nuclear Thermal Propulsion Applications. 
Past work on the behavior of fission products in carbide NTP fuels provides some useful insigbt into issues periaining to fuel material integrity, solid-solution molecular processes and potential bydrogen corrosion mechanisms (Roesmer et al. 1967 asid Bokor et al. 1991). Fundamental out-of-pile (non nuclear) corrosion reaction data is also available on related material systems, such as hot bydrogen with carbon or graphite materials (Table 4). Some of this work (Chi 1965, Chi and Landahl 1968, Burghardt 1965, and Rogers and Sesonske 1986) was performed at the bigh pressures and temperatures of interest to NTP reactor systems. In-depth characterization of carbon-hydrogen chemical reaction systems is critical to the fundamental understanding and modeling of the bydrogen corrosion process. Additionally, general reactor fuel technology data in the areas of nuclear radiation effects on similar materials, basic fuel form designs that incorporate materials such as uranium carbide, carbon, graphite, and high temperature gas reactor fuel designs, is available (Table 4). These sources of supporting fundamental data provides meaningful insight on many of the competing physical processes which must be considered in the formulation and validation of future ca-bide hydrogen corrosion modeling effort(s).

TABLE 5. General Past Engine System Testing Observations from Post-Test Inspections.

\begin{tabular}{|c|c|}
\hline TYPE & OBSERVATIONS \\
\hline Fuel Mass Loss & $\begin{array}{l}\text { - In NERVA PTOgram: } 1.0 \text { to } 0.2 \mathrm{~g} / \text { minute per Fuel } \\
\text { Element. } \\
\text { - Mass loss of } 0.2 \mathrm{~g} / \text { minute per Fuel Element } \\
\text { Achieved at the End of the NERVA Program. } \\
\text { - Fundamental Understanding on the Impact of Fuel } \\
\text { Design on Corrosion Was Lacking. }\end{array}$ \\
\hline Structural/Material Integrity & $\begin{array}{l}\text { - Substantial Cracking/Desintegration Coating the } \\
\text { Low to Medium Temperature (Mid-Axial Element } \\
\text { Positions) and Hot End Regions. } \\
\text { - Substantial Fuel Element Coolant Channel Surface } \\
\text { Cracking. } \\
\text { Thermal Conductivity Changes Measured in the } \\
\text { High Radiation Flux (Mid-Axial Element } \\
\text { Position) Region. }\end{array}$ \\
\hline
\end{tabular}

Another major outstanding technical issue identified in the review addresses the value of non-nuclear carbide material/hydrogen compatibility testing. This issue could have a major potential impact on material compatibility testing complexity and cost. It was the consensus of a forum of international technical specialists in this area that the question of nuclear versus non-nuclear material compatibility testing is still an important, open ended issue. They also stated that even if non-nuclear material compatibility tests are considered valid, the method of heating the test sample, typically induction or ohmic beating, has produced conflicting results in the past (D'yakov 1993 and Taub 1975). Such conflicting results are likely due to the difference in the thermal gradients prduced in a given material from the induction and ohmic heating methods. It is recommended that a simple, small scale experiments be performed at conditions close to those associated with NTP reactors to address this critical research testing issue. These experiments could give valuable insight into scaling non-nuclear test data to realistic NTP reactor environmental conditions, if it is possible at all.

\section{CONCLUSIONS}

Based on the initial findings of this review, it is recommended that future efforts focus on: (1) developing a corrosion model that includes all major interrelated physical process mechanisms, previously discussed, even if they are only included on a first-principle level basis, (2) acquiring fundamental single effect(s) data at realistic NTP reactor operational conditions, and (3) determining the validity of non-nuclear experimental results to the characterization of carbide material compatibility with bydrogen in NTP reactors. The first recommendation would provide guidance and direction to the proposed fundamental data gathering experimental program in Item 2 . Insight from such an effort would likely minimize the investment required to support such a test program. The experimental program, in addition to providing data to benchmark corrosion models, will contribute greatly to the understanding of the complex hydrogen corrosion phenomena. The non-nuclear testing issue has been identified as a separate, nearterm item because of its potential impact on testing complexity and cost. 
A starting point for any new modeling e : ort should include initial corrosion process scoping analysis that addresses critical issues in parametric fashion. Possible issues to be addressed include areas such as the rate of corrosion and surface cracking, and surface coating crack development and propagation if coated fuel designs are considered. Initial modeling efforts should also focus on solid-solution U-Zr-C fuel designs because of their simplicity compared to coated fuel designs As future modeling efforts evolve more competing interrelated physical process mechanisms and capabilities to analyze complex fuel designs should be incorporated into the model.

Once an accurate corrosion model is developed and verified, it could be integrated into the initial NIP engine system design process. The investment required to produce a robust, accurate corrosion model and corresponding optimization design capability will likely pay for itself many times over in terms of NTP engine system safety, reliability, and low development cost.

\section{Acknowledgments}

This work was supported by NASA Lewis Research Center, Grant No. NAG3-1346 and by the New Mexico Space Grant Consortium Program, Grant No. NGT-40019 to the University of New Mexico's Institute for Space Nuclear Power Studies. Additionally, the authors would like to acknowledge Mr. John Clark and Mr. Keith Peecook of NASA Lewis Research Center for their support. The authors would also like to express their appreciation for the support given to this effort by the Nuclear Materials Technology Division of Los Alamos National Laboratory and in particular Dr. Walter Stark.

\section{References}

Andrievski R. A., V. V. Khromozhkin, E. A. Galkin, and V. I. Mitrofanov (1969) "Evaporation of Uranium Carbide, Nitride, and Carbonitrides," Atomnaya Energiya, 26(6): 573-577.

Bernard J., A. Gautier, and A. Peres (1958) "Examples of Thermal Stress Determination Metbods Applicable to Reactor Materials," Proc. 2nd United Nations International Conferance on the Peaceful Uses of Atomic Energy, United Nations, Geneva, Switzerland, 5: 266-287.

Bokor P. C., W. L. Kirk, and R. J. Bohl (1991) "The Behavior of Fission Products During Nuclear Rocket Reactor Tests," Proc. 8ih Symp. on Space Nuclear Power Systems, CONF.910116, M. S. El-Genk and M. D. Hoover, eds., American Institute of Physics, New York, NY, AlP Conference Proceedings No. 217, 3: 1194-1206.

Borowski, S. K., J. S. Clark, M. C. Mcllwain, and D. G. Pelaccio (1992) "Nuclear Thermal Rockets: Key to Moon-Mars Exploration," Aerospace America, July 1992, 34-37.

Botts, T. E., F. L. Hom, O. C. Jones, O. W. Lazareth, H. Ludewig, J. R. Powell, and J. L. Usher (1983) "The Rotating and Fixed Bed Reactor Concepts," Air Force Rocket Propulsion Laboratory Report No. TR-83-023, November 1983.

Burghardt R. R. (1965) "Corrosion Inhibitor Tests," Westinghouse Astronautics Laboratory Report No. WANLTME-1298, Septemter 1965.

Bussard, R. W. and R. D. DeLaver (1965) Fundamenrals of Nuclear Flight, McGraw-Hill, Inc., New York, NY, 1965.

Butt, D. P. (1992) "Corrosion of $U_{x} Z_{r 1-x} C_{1-y}$ Nuclear Fuel Materials in Hydrogen Gas at High Pressures and Temperatures," 43rd Congress of the International Astronautical Federation, Washington, D.C., Paper No. LAF92-0570, 28 August - 5 September 1992.

Butt D. P. and T. C. Wallace (1993) "The U-Zr-C Ternary Phase Diagram above 2473 K." J. Am. Ceram. Soc., 76(6): 1409-1419.

Carmack, W. J., R. R. Hobbins, and P. A. Lessing (1991) "Mixed Carbide High Temperature Fuels," AIAANASA OAI Conference on Advanced SEI Technologies, Cleveland, OH, Paper No. AIAA 91-3453, 4-6 Seplember 1991. 
Chi J. W. H. (1965) "Hydrogen Corrosion of Graphite Materials and Graphite Reactor Components," Westinghouse Astronautics Laboratory Report No. WANL-TME-1151, 1965.

Chi J. W. H. and C. E. Landahl (1968) "Hydrogen Reactions with Graphite Materials at High Temperatures and Pressures," Nuclear Applications, 4: 159-169.

Childs B. G., J. C. Ruckman, and K. Buxton (1963a) "Radiation Damage in UC, UC2 and $\mathrm{U}_{2} \mathrm{C}_{3}$," Carbides in Nuclear Energy, E. T. Russell et. al., eds, Macmillian \& Co. Led, London, England, 2, 1963, 849-863.

Childs B. G. and J. C. Ruckoman (1963b) "Radiation Damage Effects in Uranium Carbide," Proc. New Nuclear Moterials Technology, including Non Metallic Fuel Elements - Vol. II, International Atomic Energy Agency, Vienna, Austria, 1963.

Clark, J. S. P. McDaniel, S. Howe, I. Helms, and M. Stanley (1993) "Nuclear Thermal Propulsion Technology: Results of an Interagency Panel in FY 1991," NASA Report No. TM-105711, April 1993.

Clarke J. T. and B. R. Fox (1967) "Reaction of Graphite Filaments with Hydrogen above $2000^{\circ} \mathrm{K}$, J. Chem. Phys, , 46: 827-836.

Dahl R. E. and H. H. Yoshikawa (1965) "Neutron-Exposure Correlation for Radiation-Damage Studies," Nuclear Science and Engineering, 21: 312-318.

Dahl R. E. (1966) "Correlation of Radiation Damage of Boronated Graphite," Pacific Northwest Laboratory Report No. BNWL-199, 1966.

Davidson J. M. and L. O. Gates (1965) "Boronated-Graphite Irradiation Studies - Final Report of Irradiation Experiments Conducted in a Hanford Reactor," Pacific Northwest Laboratory Report No. BNWL-96, June 1965.

Davidson J. M., L. O. Gates, and R. E. Nightingale (1966) "Radiation-Damage Effects in Borated Graphite," Nuclear Science and Engineering, 26: 90-98.

Degal'tsev Yu. G., N. N. Ponomarev-Stepnoy, and V. F. Kuznetsov (1987) Behavior of High-Temperature Nuclear Fuel Upon Irradiation, Atomic Energy Publishing House, Moscow, Russia, 1987.

Dobranich D. and M. S. El-Genk (1990) "Heat Transfer and Thermal Stress Analyses of a Multilayered Fuel Paricle," Proc. 7th Symp. on Space Nuclear Power Systems, CONF-900109, M. S. El- Genk and M. D. Hoover, eds., American Instituts of Physics, New York, NY, 2: 1026-1032.

D'yakov, E. K. (1993) Personal Communication, Scientific and Research Institute of SIA "LUCH", Moscow, Russia, January 1993.

El-Genk, M. S., N. J. Moriey, and D. G. Pelaccio (1993) "Pellet Bed Reactor Concepts for Nuclear Propulsion Applications," AIAASSAE/AS.ME/ASEE 29th Joint Propulsion Conference and Exhibit, Monterey, CA. Paper No. AIAA 93-2112, 28-30 June 1993.

Fedorov, G. B., V. N. Gusev, E. A. Smirkov, G. I. Solov'ev, and S. S. Yankulev (1972) "Component Diffusion in UC-7.C System," Translated from Alomnaya Engeriya, 33(1): 584-586.

Finseth, J. L. (1991) "Rover Nuclear Rocket Engine Programs; Overview of Rover Engine Tests - Final Report," NASA Contract No. NAS 8-37814, February 1991.

Freas D. G., A. E. Austin, and F. A. Rough (1961) "Mechanisms of Irradiation Damage in Uranium Monocarbide," Symp. on Radiation Effects in Refractory Fuel Compounds, ASTM Special Techical Publication No. 306, 1961.

Fries R. A. (1962) "Vaporization Behavior of Niobium Carbide," J. Chem. Phys., 37,2: 320-327.

Green L. Jr. (1959) "High-Temperature Creep of Uranium-Loaded Graphites," Nuclear Fuel Elements, Hauser H. H. and J. F. Schumar, eds, Reinhold Publishing Corporation, New York, NY, 1959, 274-286. 
Homan, F. J., J. M. Napier, and C. S. Caldwell (1991) "Particle Fuels Technology for Nuclear Thermal Propulsion," AIAANASA OAI Conference on Advanced SEI Technologies, Cleveland, OH, Paper No. AIAA 91 3457, 4-6 September 1991.

Hunter L. P. (1959) "Effect of Fission Recoil Fragments on the Thermal Conductivity of Graphite," J. Applied Physics, 30: 1969-1975.

Juveland A. C., H. P. Deinken, and J. E. Dougherty (1963) "Loss of Zirconiun and Uranium from Fluidized Beds of ZrC and UC-ZrC Particles at High Temperatures," Los Alamos Scientific Laboratory Report No. LAMS-2994, December 31, 1963.

Kempter C. P. and M. R. Nadler (1960) "Thermal Decomposition of Niobium and Tantalim Monocarbides," J. Chem. Phys., 32(5): 1477-1481.

Kochka E. L. (1969) "The Microstructure of NbC Coatings," Westinghouse Astronuclear Laboratory Report No. WANL-TME-1939, July 1, 1969.

Koenig, D. R. (1986) "Experience Gained from the Space Nuclear Rocket Program (Rover)," Los Alamos National Laboratory Report No. LA-10062-H, May 1986.

Krakowski, R.A. and D. R. Olander (1968) "Survey of the Literature on the Carbon-Hydrogen System," Lawerence Radiation Laboratory Report No. UCRL-19149, University of California, Berkeley, CA, 1968.

Lyon L. L. (1973) "Performance of (U,Zr)C-Graphite (Composite) and of (U,Zr)C (Carbide) Fuel Elements in the Nuclear Fumace 1 Test Reactor," Los Alamos Scientific Laboratory Reporn No. LA-5398-MS, September 1973.

MacMillan, D. P. (1991) "Overveiw of Fuel Element Development and Mass Loss Rate Experiments on UraniumZirconium-Carbide Fuel," Proc. 8th Symp. on Space Nuclear Power Systems, CONF-910116, M. S. El-Genk and M. D. Hoover, eds., American Institute of Physics, New York, NY, AlP Conference Proceedings No. 217, 3: 1037-1044.

Matthews R., H. Blair, K. Chidester, and K. Davidson (1991) "Carbide Fuels for Nuclear Thermal Propulsion," AIAA/NASAVAI Conference on Advanced SEI Technologies, Cleveland, OH, Paper No. AIAA-91-3455, 4-6 September 1991.

Nightingale R. E. (ed.) (1962) Nuclear Graphite, Academic Press, New York, NY, 1962.

Nightingale R. E. (1964) "Radiation Effects in Graphite," MATERLALS AND FUELS for High - Temperature Nuclear Energy Applications, Simnad M. T. and L. R. Zumwalt, eds, The M.I.T. Press, Cambridge, MA, 1964, 287-312.

Nikol'skaya T. A., R. G. Avarbe, and Yu. N. Vilk (1968) "Temperature and Concentration Dependence of the Thermodynamic Fuunctions of Niobium and Tantalum Carbides," Russian J. Phys. Chem, 42(3): 337-338.

Robertson J. A. L. (1969) Irradiation Effects in Nuclear Fuels, Gordon and Breach Science Publishers, New York, NY, 1969.

Roesmer J., W. A. Henninger, and G. T. Rymer (1967) "Investigation on Losses of Fission Products by Diffusion and by Hydrogen-Induced Corrosion From NERVA Fuels," Westinghouse Astronautics Laboratory Report No. WANL-TME-1696, November 1967.

Rodgers J. D. and Sesonske A. (1986) "Analysis of Graphite-Hydrogen-Methane Kinetics Above 1600 K," Nuclear Technology, 73: 236-242.

Samsonov G. V., (ed.) (1974) Refractory Carbides, Consultants Bureau, London, England, 1974.

Sanders W. A. (1965) "Rates of Hydrogen-Graphite Between $1550^{\circ}$ and $2260^{\circ}$ C," NASA TN D-2738. 
Santandrea, R. P. (1993) "Thermodynamics of Refractory Carbides: An Overview," To be published in the Proc. Workshop on Hydrogen Corrosion in Nuclear Thermal Propulson Reactors, Albuquerque, NM, 9 January 1993.

Sayers J. B., K. S. B. Rose, J. H. Coobs, G. P. Hauser, and C Vivante (1963) "The Iradiation Behaviour of Coated Particle Fuel," Carbides in Nuclear Energy, E. T. Russell et. al., eds, Macmillian \& Co. Ltd, London, 2, 1963, 919-962.

Simmons J. H. W., B. T. Kelly, P. T. Nettley, and W. N. Reynolds (1965) "The Irradiation Behaviour of Graphite," Proc. 3rd United Nations International Conferance on the Peacefil Uses of Atomic Energy, United Nations, Geneva, Switzerland, 9: 344.

Stafford et al. (1991) America at the Threshold-America's Space Exploration Initiative, Report of the Synthesis Group, Available from the Superintendent of Documents, U. S. Government Printing Office, Washington, D.C., June 1991.

Storms, E. K. (ed.) (1967) The Refractory Carbides, Academic Press, New York, NY, 1967.

Storms E., B. Calkins, and A. Yencha (1969) "The Vaporization Behavior of the Defect Carbides Part I: The Nb-C System," High Temp. Sci., 1: 430-455.

Storms, E. and J. Griffin (1973a) "Thermodynamics and Phase Relationships of the Zirconium - Uranium - Carbide System," High Temp. Sci., 5: 423-437.

Storms E. K. and J. Griffin (1973b) "The Vaporization Bebavior of the Defect Carbides. IV. The Zirconium Carbon System," High Temp. Sci., 5: 291-310.

Storms E. K. and P. Wagner (1973c) "Thermal Conductivity of Sub-Stoichometric ZrC and NbC," High Temp. Sci., 5: 454-462.

Storms, E. K., D. Hanson, W. Kirk, and P. Goldman (1991) "Effect of Fuel Geometry on the Life TimeTemperature Performance of Advanced Nuclear Propulsion Reactors," AIAANASAOAI Conference on Advanced Technologies, Cleveland, OH, Paper No. AIAA 91-3454, 4-6 September 1991.

Storms, E. K. (1992) "The Behavior of $\mathrm{ZrC}_{1-\mathrm{x}}$ in Flowing Hydrogen at Very High Temperatures," Los Alamos National Laboratory Report No. LA-12043-MS, January 1992.

Taub, J. M. (1975) "A Review of Fuel Element Development for Nuclear Rocket Engines," Los Alamos Scientific Laboratory Report No. LA-5931, June 1975.

Taylor R., B. T. Kelly, and K. E. Gilchrist (1969) "The Thermal Conductivity of Fast Neutron Irradiated Graphite," J. Phys. Chem. Solids, 30: 2251-2267.

Tobin J. M., L. M. Adelberg, L. H. Cadoff, and W. F. Brizes (1965) "Carbon Diffusion in the Group IVB and VB Transitions Elements Monocarbides," Westinghouse Astronautics Laboratory Report No. WANL-TME-1336, December 1965.

Wagner, P. (1992) "Material Science Experience Gained from the Space Nuclear Rocket Program: Insulators, "Los Alamos National Laboratory Report No. LA-12320-MS, July 1992.

Wallace, T. C. (1991) "Review of Rover Fuel Element Protective Coating Development at Los Alamos," Proc. 8th Symp. on Space Nuclear Power Systems, CONF-901116, M. S. El- Genk and M. D. Hoover, eds., American Institute of Physics, New York, NY, AIP Conference Proceedings No. 217, 3:1024-1036.

Wallace T. C. and D. P. Butl (1993) "Diffusion and Vaporization of Transition Metal Carbides as it Relates to Diffusion Coupled Vaporization Processes: A Review," Submitted to the Proc. of Workshop on Hydrogen Corrosion in Nuclear Thermal Propulsion Reactors, 10th Symposium on Space Nuclear Power and Propulsion, Albuquerque, NM, 9 January 1993. 

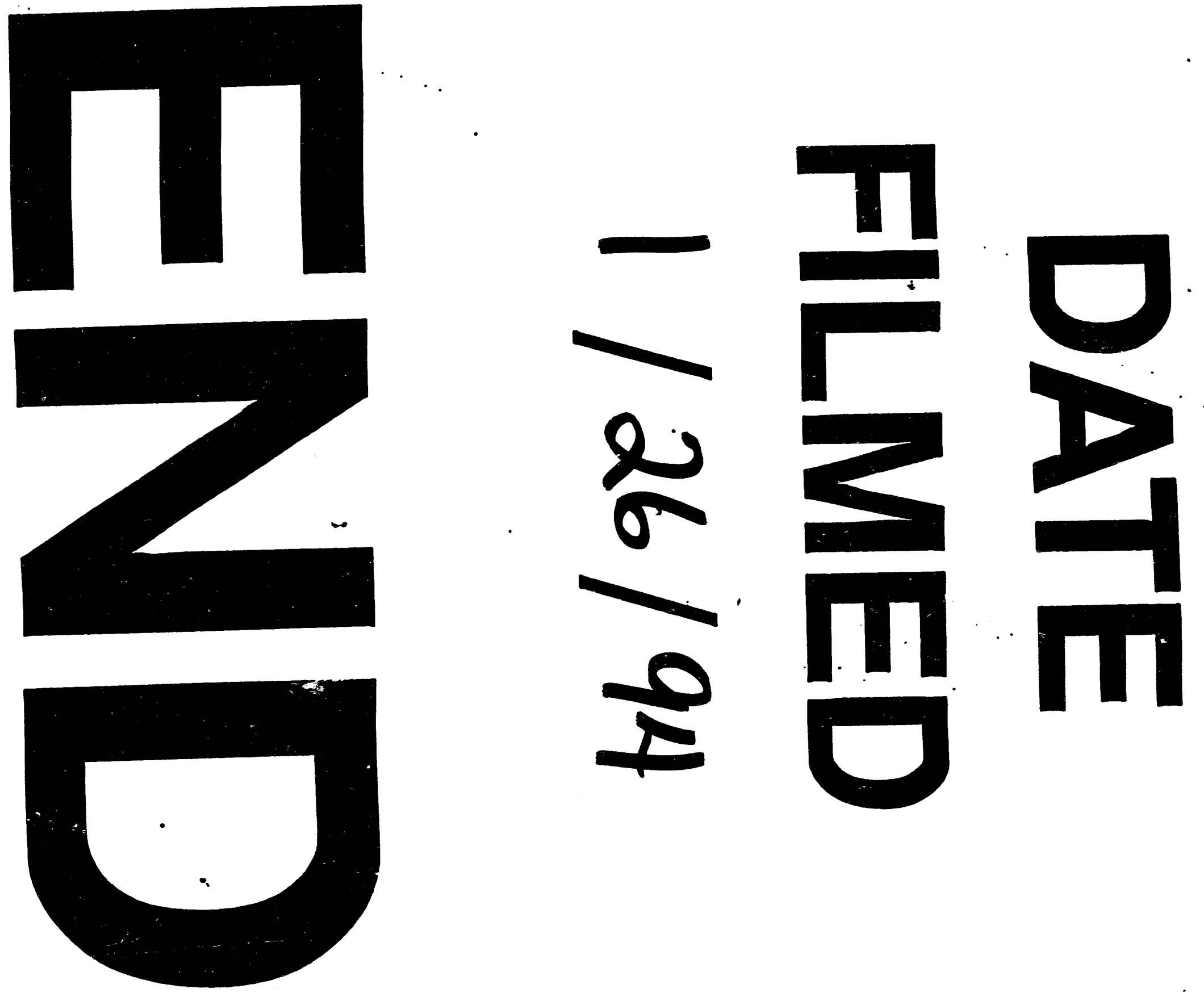
